\title{
Nigrostriatal dynein changes in A53T alpha-synuclein
}

\section{transgenic mice [version 1; peer review: 1 approved, 2}

\section{approved with reservations]}

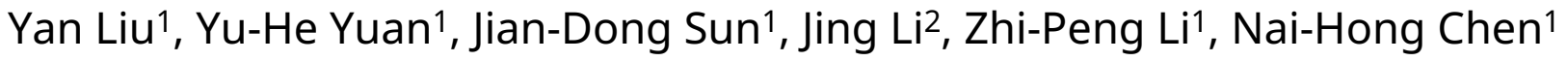 \\ ${ }^{1}$ State Key Laboratory of Bioactive Substances and Functions of Natural Medicines, Department of Pharmacology, Institute of \\ Materia Medica, Chinese Academy of Medical Sciences and Peking Union Medical College, Beijing, 100050, China \\ ${ }^{2}$ Tianjin University of Traditional Chinese Medicine, Tianjin, 300193, China
}

V1 First published: 11 Mar 2014, 3:68

https://doi.org/10.12688/f1000research.3507.1

Latest published: 11 Mar 2014, 3:68

https://doi.org/10.12688/f1000research.3507.1

\begin{abstract}
The accumulation of misfolded a-synuclein is mechanistically linked to neurodegeneration in Parkinson's disease (PD) and other alphasynucleinopathies. However, how alpha-synuclein causes neurodegeneration is unresolved. Several studies have supported the involvement of dynein, the major motor for retrograde axonal transport in alpha-synuclein-dependent neurodegeneration, especially in the nigrostriatal system. Therefore, we examined the nigrostriatal dyneins in transgenic mice that overexpress human A53T alpha-synuclein and recapitulate key features of a PD-like neuronal synucleinopathy. Age-matched nontransgenic littermates were used as controls. The results demonstrated that the protein level of dynein was decreased in the striatum, whereas it was elevated in the substantia nigra. Double immunostaining results revealed that the reduction in dynein level was associated with aggregation of A53T asynuclein in the striatum. Furthermore, we performed a quantitative analysis of motor behaviors in A53T alpha-synuclein transgenic mice and controls using a modified open field test. We demonstrated that the protein level of dynein in the striatum was significantly correlated with the motor behaviors. Together, our data indicate that dynein changes in the nigrostriatal system of A53T alpha-synuclein transgenic mice may contribute to their severe movement disorder.
\end{abstract}

Keywords

Dynein; alpha-Synuclein; Open field test; Parkinson's disease

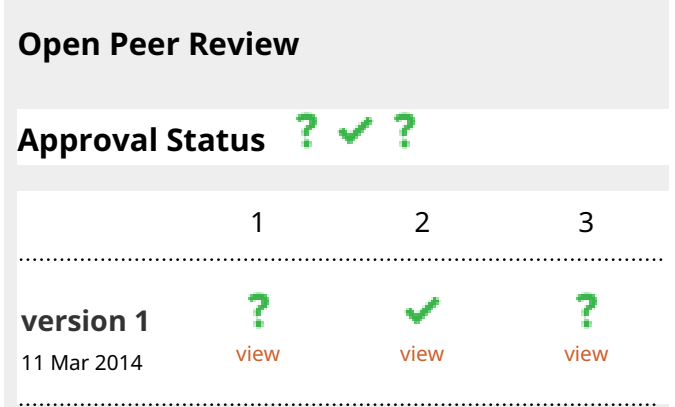

1. James B Koprich, Toronto Western Hospital, University Health Network, Toronto, ON, Canada

2. Gerardo Morfini, University of Illinois at Chicago, Chicago, IL, USA

3. Abraham Acevedo-Arozena, Harwell Science and Innovation Campus, Oxford, UK

Any reports and responses or comments on the article can be found at the end of the article. 
Corresponding author: Nai-Hong Chen (chennh@imm.ac.cn)

Competing interests: No competing interests were disclosed.

Grant information: This work was supported by National Natural Science Foundation of China Grants (No. 30973887, No. 81073078, Key Program No. U832008), National Key Sci-Tech Major Special Item (No. 2012ZX09301002-004), and Studies on Structure and function of Bioactive Substances from Natural Medicines (IRT1007).

The funders had no role in study design, data collection and analysis, decision to publish, or preparation of the manuscript.

Copyright: ( $\odot 2014$ Liu Y et al. This is an open access article distributed under the terms of the Creative Commons Attribution License, which permits unrestricted use, distribution, and reproduction in any medium, provided the original work is properly cited. Data associated with the article are available under the terms of the Creative Commons Zero "No rights reserved" data waiver (CCO 1.0 Public domain dedication).

How to cite this article: Liu Y, Yuan YH, Sun JD et al. Nigrostriatal dynein changes in A53T alpha-synuclein transgenic mice [version 1; peer review: 1 approved, 2 approved with reservations] F1000Research 2014, 3:68 https://doi.org/10.12688/f1000research.3507.1

First published: 11 Mar 2014, 3:68 https://doi.org/10.12688/f1000research.3507.1 


\section{Introduction}

$\alpha$-Synuclein abnormalities are mechanistically linked to the pathogenesis of Parkinson's disease (PD) and other $\alpha$-synucleinopathies. $\alpha$-Synuclein is the major component of Lewy bodies, the neuropathological hallmarks of $\mathrm{PD}^{1,2}$. Duplication, triplication or mutations in the $\alpha$-synuclein gene cause some forms of familial $\mathrm{PD}^{3,4}$. However, the mechanism whereby $\alpha$-synuclein promotes neurodegeneration remains unclear.

Dyneins are minus end-directed microtubule motors that move cargoes such as mitochondria, organelles and proteins from the distal ends of axons toward neuronal cell bodies ${ }^{5,6}$. Dynein is the major motor of retrograde axonal transport, and it is also the molecular motor responsible for the transport of misfolded proteins to be degraded. Therefore, it is crucially involved in the appearance and clearance of protein aggregates ${ }^{7}$. Several studies have supported the involvement of dynein in the neurodegeneration associated with PD. First, recent studies suggest that axonal transport disruption may be causal to disease progression in $\mathrm{PD}^{8,9}$. Alterations in axonal transport motor proteins have been observed in postmortem patient brain samples ${ }^{9}$ and treatment with 1-methyl-4-phenyl-1,2,3,6tetrahydropyridine (MPTP), a PD-relevant injury, leads to defective axonal transport, including increased dynein-dependent transport ${ }^{10}$. Second, a number of dynein-dependent processes, including autophagy or clearance of aggregation-prone proteins, are found to be defective in $\mathrm{PD}^{11}$. In all cases, defects in axonal transport and autophagy occurring in PD indicate that dynein may be a central factor in PD pathology. Interestingly, experimental evidence suggests that $\alpha$-synuclein mutations (A53T, A30P) might lead to axonal transport defects both in vivo and in vitro ${ }^{8,9,12}$. Therefore, we hypothesized that the neurodegeneration observed in the A53T mutant human $\alpha$-synuclein transgenic ( $\mathrm{Tg}$ ) mouse model of $\alpha$-synucleinopathy was associated with alterations of dynein.

In this study, we first evaluated the motor function of A53T human $\alpha$-synuclein Tg mice and age-matched non-transgenic (nTg) littermates using a modified open field test. Unlike previous studies that only provided behavioral descriptions, in this study, we quantified behavior. We then examined the expression of dynein in the striatum and substantia nigra (SN), as dynein defects have been mostly studied in the nigrostriatal system in previous research? ${ }^{9}$. To evaluate whether changes of dynein were related to $\alpha$-synuclein aggregation, double immunostaining for $\alpha$-synuclein and dynein was performed. In addition, we analyzed the correlation between the motor behaviors and the protein level of dynein in the striatum. Our findings reveal that dynein changes in the nigrostriatal system of A53T $\alpha$-synuclein $\mathrm{Tg}$ mice may contribute to their dramatic motor phenotype.

\section{Materials and methods}

\section{Animals}

Animal experiments were conducted in accordance with the principles and procedures of the US National Institutes of Health Guide for the Care and Use of Laboratory Animals. All protocols were approved by the Institutional Animal Care and Use Committee of Peking Union Medical College and Chinese Academy of Medical Sciences.
The generation of Tg mice expressing high levels of mutant A53T $\alpha$-synuclein under the control of the mouse prion protein $(\operatorname{PrP})$ promoter has been described ${ }^{13}$. Mice expressing A53T $\alpha$-synuclein (line M83), but not mice expressing wild type $\alpha$-synuclein, develop adult-onset progressive motor deficits ${ }^{13}$. According to the first report of M83 mice ${ }^{13}$, about $50 \%-70 \%$ of mice at 10-14 months of age develop the motor phenotype. Original mice were obtained from The Jackson Laboratory. We purchased the mice from Model Animal research Center of Nanjing University. In all experiments 12 male M83 mice aged between 10-14 months were used. Eight control mice were age-matched, male, nTg littermates. No statistical method was used to pre-determine sample size; however, the sample size per experiment was based on our previous successful experiments and publications. Mice were raised on a 12-h light/dark cycle, with food and water available ad libitum and were housed in groups of four per cage.

\section{Modified open field test}

The procedure was modified from the protocol previously described $^{14}$. The apparatus consisted of a rectangular area of $32 \times$ $32 \mathrm{~cm}$ which was divided into 64 squares of $4 \times 4 \mathrm{~cm}$. An uneven surface (32 cm in diameter) made of mesh wire (200 mesh) was raised by a ring in this area. A platform ( $4 \mathrm{~cm}$ in diameter) was placed in the middle of the uneven surface (Figure 1a). The day before the test, the mice were given two trials. During the test, the animals were placed on the platform and their activities were assessed during the subsequent 6 min period. The performance of mice was video recorded. Horizontal locomotion (number of grids crossed) and latency (time to get down from the platform) were analyzed thereafter.

\section{Western blotting}

Total protein extracts from striatum and ventral midbrain were prepared and western blot analyses were performed as described previously ${ }^{15,16}$. Primary antibodies were as follows: mouse anti- $\alpha-$ synuclein (Syn204) monoclonal antibody (Cell Signaling Technology, \#2647), mouse anti-dynein monoclonal antibody (Millipore, \#MAB1618), rabbit anti-dynein intermediate chain polyclonal antibody (Abcam, \#ab81507). Horseradish peroxidase-conjugated secondary antibody (KPL, 1:5000) and enhanced chemiluminescence solution (Applygen Technologies Inc) were used for detection. Bands were quantified using Gel-Pro Analyzer software (Media Cybernetics).

\section{Immunohistochemistry and double-labeling immunofluorescence}

Mice were anesthetized with $10 \%$ chloral hydrate and then perfused through the heart for 3 min with PBS followed by $4 \%$ paraformaldehyde $(50-100 \mathrm{ml})$. The brains were then removed, postfixed with $4 \%$ paraformaldehyde for 4 hours, embedded in paraffin as described by OpenWetWare (http://openwetware.org/wiki/Paraffin_embedding_and_sectioning), and cut into $3 \mu \mathrm{m}$ serial sections using Leica tissue slicer (RM2235). Stainings were all performed according to our protocol for immunostaining ${ }^{16,17}$. Immunohistochemistry was performed with mouse anti-dynein antibody (Millipore, 1:100). Double immunofluorescence was performed by using rabbit anti-dynein antibody (Abcam, \#ab121209, 1:50) and mouse 


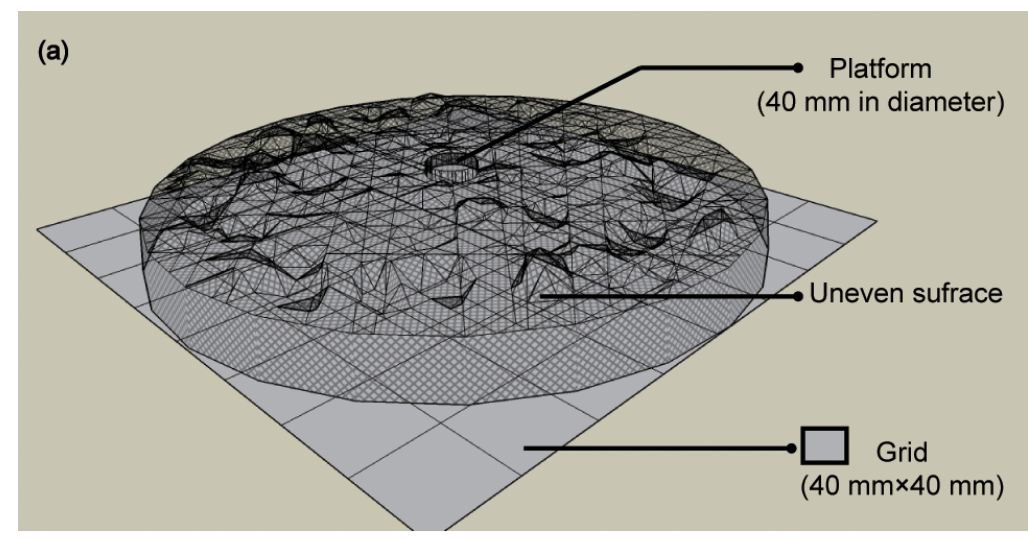

(b)

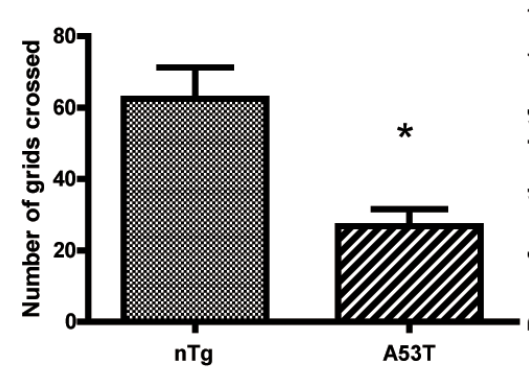

(c)

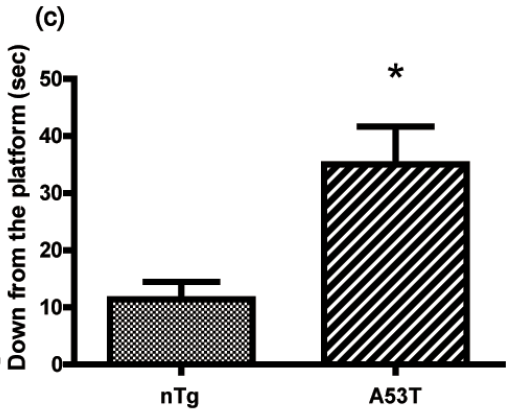

Figure 1. Motor behaviors of A53T $\alpha$-synuclein Tg mice (10-14 months old) and age-matched nTg littermates were evaluated a using modified open field test. (a) 3-D model for modified open-field test apparatus. The data (mean \pm SEM) show the number of grids crossed (b) and the time to get down from the platform (c) in a 6 min period in an open field (nTg, $n=8$; A53T, $n=12$ ). " $p<0.05$ compared to nTg.

anti- $\alpha$-synuclein antibody (Cell Signaling Technology, \#2647, 1:50). Immunostaining was visualized by 3,3-diaminobenzidine or by fluorescein isothiocyanate and Alexa 546 (Invitrogen, 1:100) and was examined by either regular light or laser-scanning confocal microscope (Zeiss, Germany).

\section{Image analyses}

Image analyses were performed according to previously published procedures $^{9,18,19}$. Briefly, a $1 \times 0.5 \mathrm{~mm}^{2}$ contour was placed over the striatum at low magnification ( $\times 4$ objective) and the optical density of dynein-immunoreactivity (dynein-ir) within the contour were measured under high magnification $(x 40$ objective). Each subfield of the substantia nigra pars compacta ( $\mathrm{SNpc}$ ) was manually outlined at low magnification $(\times 4$ objective). $50 \%$ of the fields were randomly selected. Then, at high magnification ( $\times 40$ objective), each selected field was retrieved automatically. Optical density measurements were performed on individual tyrosine hydroxylasepositive neurons which had been stained on adjacent sections. The optical density of dynein-ir in the striatum and SNpc was measured for six sections per animal (1 out of every 20 serial sections) using Image-Pro Plus software (Media Cybernetics).

\section{Statistical analysis}

The results are expressed as the mean \pm SEM. Statistical significances were determined by two-tailed Student's t-test. Pearson's correlation test was used to analyze the correlation between motor behaviors and dynein protein level. The level of statistical significance was set at $p<0.05$. All analyses were conducted by the statistical software package SPSS 13.0 for Windows.

\section{Results}

Modified open field test

Consistent with a previous report ${ }^{13}$, a few homozygous mice expressing A53T $\alpha$-synuclein developed a progressively severe motor phenotype at 8 months of age. No behavioral tests were performed on the transgenic mice before 8 months of age. In the present study, we used a modified open field test ${ }^{14}$ to quantitatively evaluate the motor behaviors of the mice (Figure 1a). A53T human $\alpha$-synuclein $\mathrm{Tg}$ mice showed a $60 \%$ decrease in the number of total grids crossed compared to nTg mice ( $p>0.05$, Figure $1 \mathrm{~b})$, and A53T mice took much longer (3-fold) to get down from the platform than $\mathrm{nTg}$ mice $(p<0.05$, Figure $1 c)$, indicating decreased motor function.

\section{Protein level of dynein}

Western blotting was used to detect dynein protein expression in the striatum and ventral midbrain. The levels of dynein were significantly decreased in the striatum of A53T human $\alpha$-synuclein $\mathrm{Tg}$ mice compared to $\mathrm{nTg}$ mice $(p<0.001$, Figure $2 \mathrm{a}, \mathrm{b})$. In contrast to the results in the striatum, the expression levels of dynein were upregulated in the ventral midbrain $(p<0.001$, Figure $2 \mathrm{a}, \mathrm{b})$. 
(a)

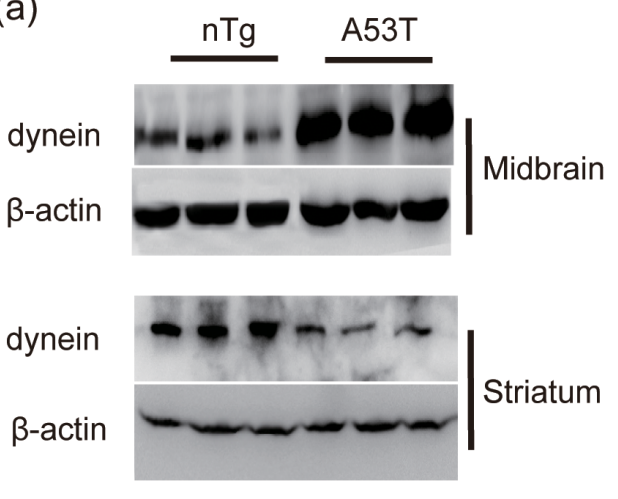

(b)

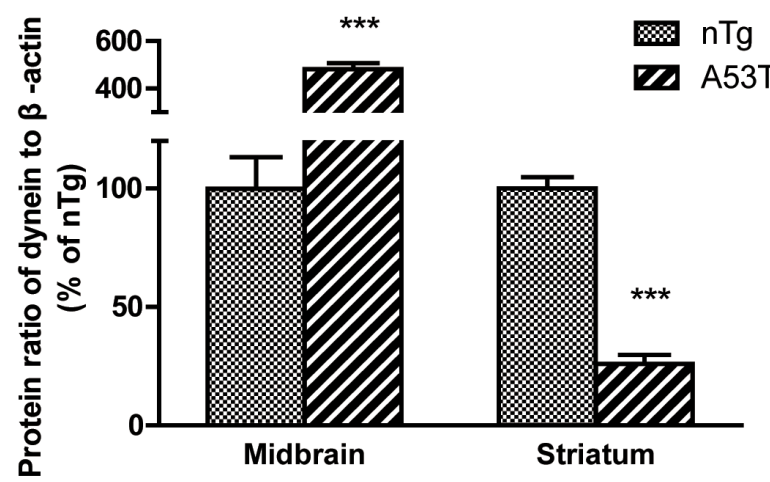

Figure 2. Western blot analyses of dynein in the striatum and midbrain. (a) Representative western blot images of dynein and $\beta$-actin in the striatum and midbrain are shown, and (b) the results were quantified (mean \pm SEM) and normalized by the averaged value of nTg group. $n T g, n=5 ;$ A53T, $n=8 ; " * * 0<0.001$ compared to $n T g$.

Next, dynein immunohistochemistry was performed on the nigrostriatal sections of the two groups (Figure 3). An obvious suppression of the dynein immunoreactivity occurred in the striatum in A53T human $\alpha$-synuclein Tg mice compared with that of $\mathrm{nTg}$ mice (Figure 3c, d). Consistent with the increased protein level of dynein in the ventral midbrain, dynein immunoreactivity in the SNpc was elevated in the transgenic mice (Figure 3e, f). Abundant dynein accumulation was seen in neuronal perikarya in the SNpc (Figure 3f). Quantitative analysis of dynein-ir optical density is shown in Figure $3 \mathrm{~g}$ and $\mathrm{h}$. The data showed that dynein-ir optical density was significantly decreased in the striatum of A53T $\alpha$-synuclein $\mathrm{Tg}$ mice $(p<0.001)$, whereas it was increased in the SNpc $(p<0.001)$.

\section{Co-localization of dynein and $\boldsymbol{\alpha}$-synuclein in the striatum of Tg mice}

Consistent with a previous report ${ }^{13}$, we observed A53T $\alpha$-synuclein inclusions in the striatum (Figure 3i). Co-localization studies revealed that a marked reduction in dynein immunoreactivity was observed in striatal cells featuring $\alpha$-synuclein-immunoreactive inclusions compared to cells without $\alpha$-synuclein inclusions (Figure 3i-k), suggesting that the reduction in dynein level was associated with accumulation of A53T $\alpha$-synuclein.

\section{Relationships between motor behaviors and protein level of dynein}

Figure 4 shows a significant positive correlation between the number of total grids crossed and the dynein protein level in the striatum (Figure 1a, $\mathrm{r}=0.7688, p<0.01$ ), as well as a negative correlation between the latency to get down from the platform and the dynein protein level in the striatum (Figure $1 \mathrm{~b}, \mathrm{r}=-0.6559, p<0.05$ ). These data imply that the dynein protein level in the striatum was correlated with the motor behaviors.

Raw data from behavior tests and dynein protein levels

4 Data Files

http://dx.doi.org/10.6084/m9.figshare.954933

\section{Discussion}

The major finding of this study is that dynein changes in expression occurred in the nigrostriatal system of A53T human $\alpha$-synuclein $\mathrm{Tg}$ mice, with the level of dynein increasing in the $\mathrm{SN}$, and decreasing in the striatum. At the behavioral level, the alterations were accompanied by significantly reduced horizontal locomotion and prolonged latency in modified open field test (Figure 1). A correlation analysis showed that the motor behaviors were significantly related to the protein level of dynein in the striatum (Figure 4). Furthermore, analysis of the co-localization of dynein and $\alpha$-synuclein in the striatum indicated that the reduction in dynein level was associated with accumulation of A53T $\alpha$-synuclein (Figure 3).

The severe motor phenotype was associated with the formation of $\alpha$-synuclein inclusions in mice expressing A53T human $\alpha$-synuclein; therefore M83 Tg mice represent an excellent model of $\alpha$-synucleinopathies (especially familial PD) ${ }^{13}$. The 10-14 month old Tg mice were too weak to perform in the traditional behavior tests such as the rotarod test and the pole test ${ }^{20,21}$, and therefore we used a modified open field test that combines the traditional pole test and open field test. The number of grids crossed was equivalent to the square crossings in the traditional open-field test, a measure of general locomotor activity. The latency to get down from the platform was equivalent to the time to orient downwards in the traditional pole test, which has been used to assess basal gangliarelated movement disorders in mice ${ }^{20}$. The advantages of this method are the following: (i) the height of the platform is far lower than that of the pole, and, therefore, mice are protected from injuring themselves; (ii) the uneven surface increases the difficulty of movement, thus making the differences in motor function more obvious.

Our data demonstrated that the critical retrograde axonal transport motor dynein was markedly reduced in the striatum of A53T $\alpha$-synuclein $\mathrm{Tg}$ mice, whereas it was upregulated in the $\mathrm{SN}$, indicating defects in retrograde axonal transport in the nigrostriatal pathway. Recent reports have demonstrated that $\alpha$-synuclein can interact with dynein-containing complexes and its transport involves 
(a)

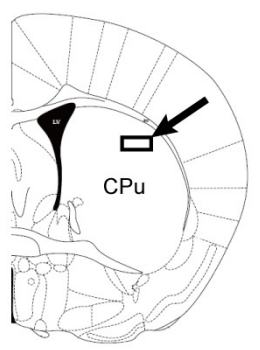

Bregma $0.14 \mathrm{~mm}$ (b)

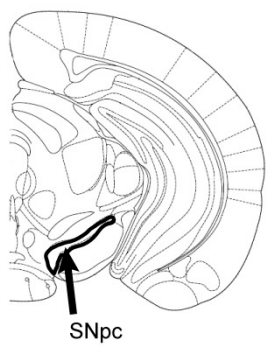

Bregma -3.08 mm
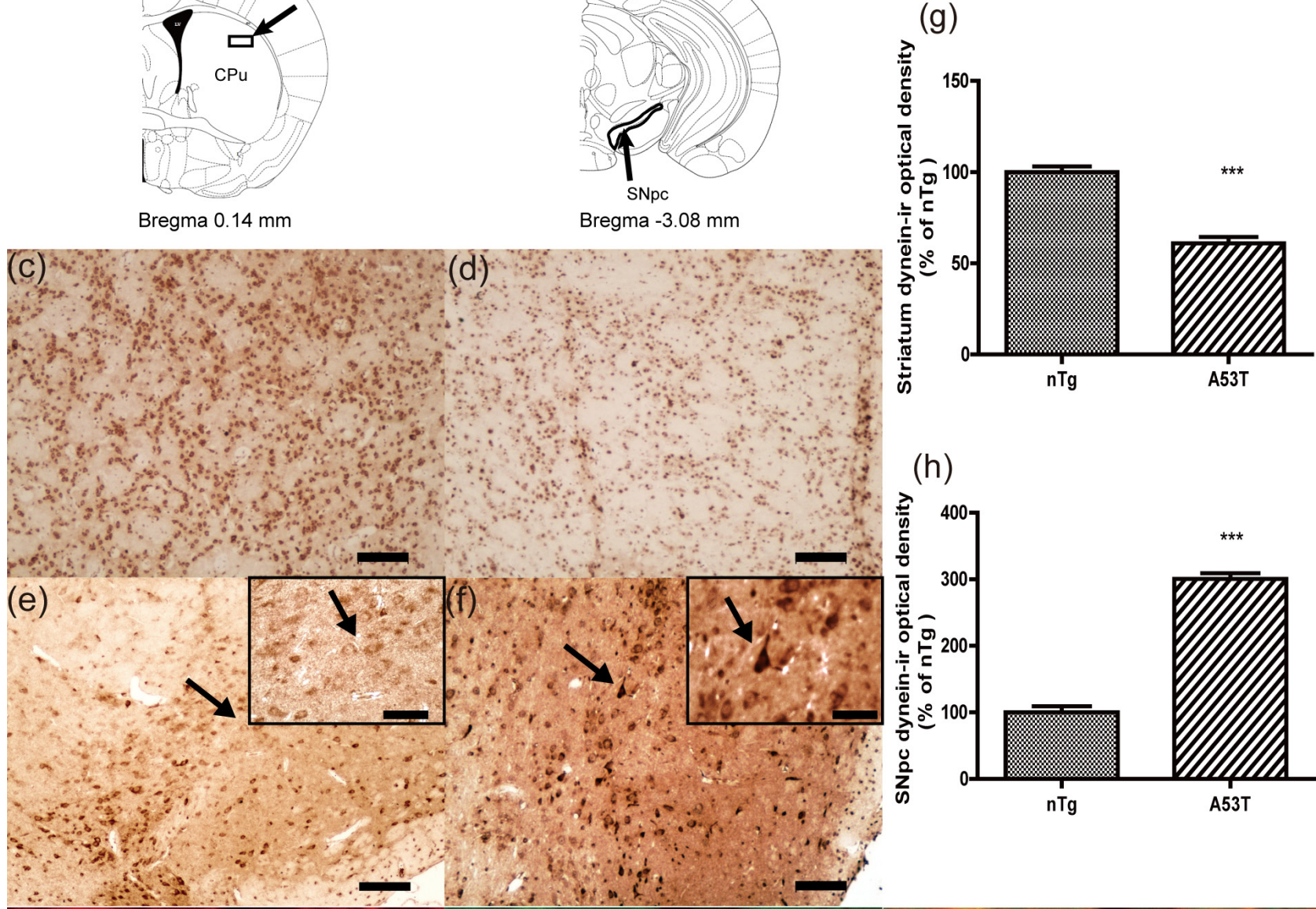

(h)

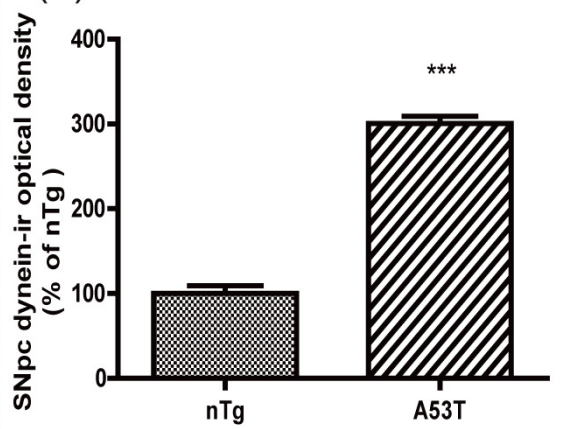

(i)
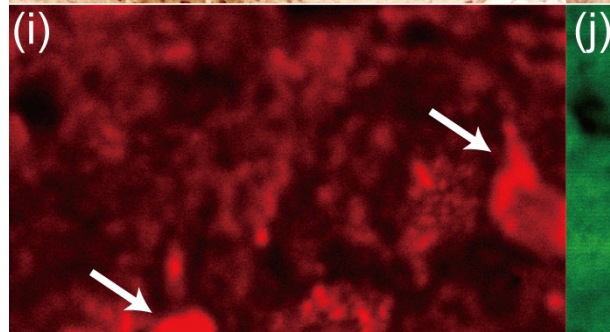

a-Synuclein $(\mathrm{H})$
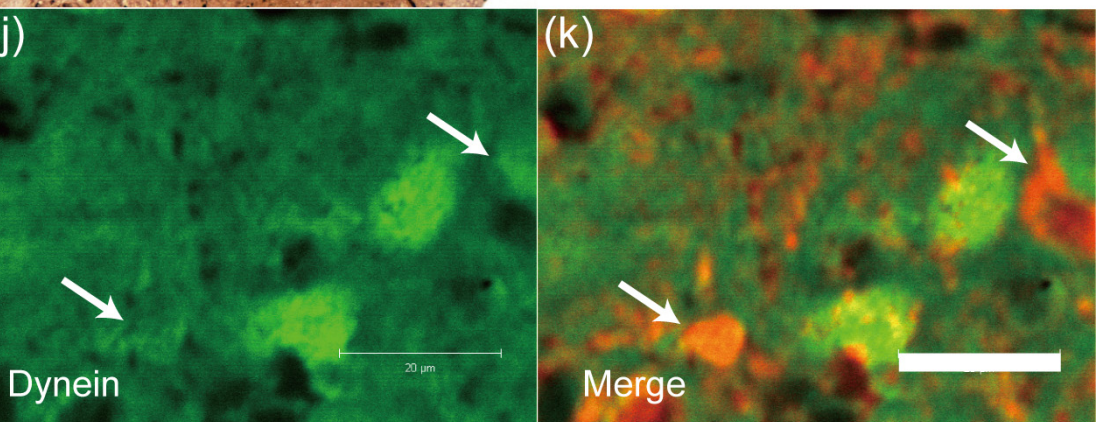

Figure 3. Immunohistochemical analyses of dynein in the striatum and substantia nigra pars compacta (SNpc). Optical density of dynein-immunoreactivity was quantified in the striatum and SNpc as shown in $(\mathbf{a})$ and $(\mathbf{b})^{26}$. The photomicrographs show the distribution of immunoreactivity for dynein in the striatum (c-d) and SNpc (e-f). Sections were prepared from nTg mice (c, e) and A53T $\alpha$-synuclein Tg mice $(\mathbf{d}, \mathbf{f})$. The immunoreactivity for dynein was decreased in the striatum of A53T $\alpha$-synuclein Tg mice but increased in the SNpc. Insets in (e) and (f) are high-magnification images of the region indicated by arrows. Abundant dynein accumulation in neuronal perikarya in the SNpc is indicated by arrows in $\mathrm{f}$. The optical density of dynein-ir in the striatum $(\mathbf{g})$ and $\mathrm{SN}(\mathbf{h})$ was quantified (mean \pm SEM) and normalized by the averaged value of $n T g$ group $(n=3)$. "** $p<0.001$ compared to $n T g$. A section of the striatum from a 12-month-old homozygous M83 mouse was double labeled with anti- $\alpha$-synuclein (i, red) and dynein (j, green) antibodies. Note that dynein immunofluorescence intensity was extensively reduced in cells with $\alpha$-synuclein inclusions (arrows, $\mathbf{i}-\mathbf{k})$. Scale bar $=50 \mu \mathrm{m}$ in $(\mathbf{c}-\mathbf{f}) ; 20 \mu \mathrm{m}$ in insets and (i-k). 

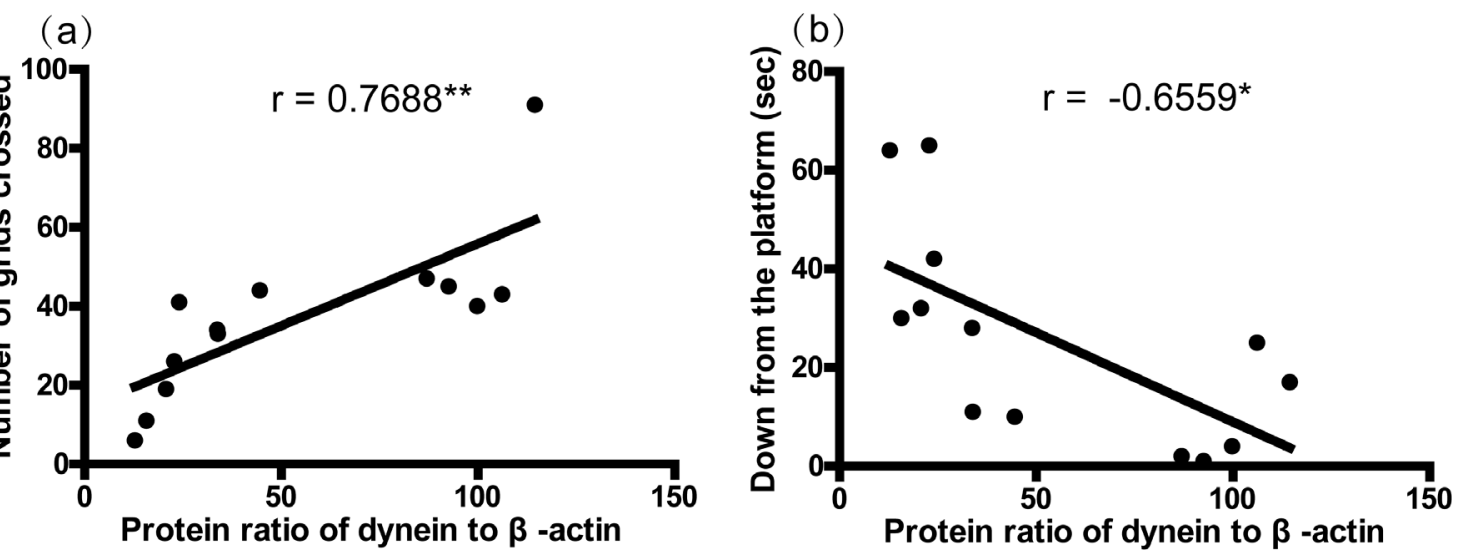

Figure 4. Correlations between the motor behaviors and dynein protein levels in the striatum $(n=13 ; n T g, n=5 ;$ A53T, $n=8)$. The correlation analysis between number of grids crossed (a), time to get down from the platform (b), and the protein levels of dynein in the striatum was performed by the Pearson's correlation test. Asterisks $\left({ }^{*}\right)$ show the significance of the correlation (two tailed). " $p<0.05$, " $p<0.01$.

dynein motor protein ${ }^{22}$. The reduction in retrograde axonal transport might produce $\alpha$-synuclein aggregation in neuronal processes (Lewy neurites in the striatum), which provides a reasonable explanation for the fact that aggregation of $\alpha$-synuclein in neuronal processes was a major feature of M83 $\mathrm{Tg}$ mice $^{13}$. On the other hand, mutant A53T $\alpha$-synuclein is strongly dependent on autophagy for their clearance ${ }^{23}$, a dynein-dependent process ${ }^{7}$. In effect, the abnormalities of dynein would affect the clearance of A53T mutant $\alpha$-synuclein protein by autophagy. Indeed, our co-localization results suggested that the reduction in dynein level was associated with accumulation of A53T $\alpha$-synuclein in the striatum (Figure 3).

Correlation analysis between motor behaviors and dynein demonstrated that the motor behaviors were related to the alteration of dynein protein level in the striatum, which supports the involvement of dynein in neurodegeneration associated with PD and other $\alpha$-synucleinopathies. In accordance with our findings, a large body of evidence has demonstrated that axonal transport machinery is impaired during neurodegeneration, and likely contributes to this condition $^{24,25}$.

Dynein alterations have been detected in several $\alpha$-synuclein-based models. A report indicated that viral over-expression of human mutant (A53T) $\alpha$-synuclein resulted in an increase of dynein in striatum but no change in the SN 8 weeks after the injection ${ }^{8}$. Another report showed a decrease of dynein in the SN 6 weeks following viral A30P $\alpha$-synuclein over-expression?. These divergent results may be related to the use of different mutant $\alpha$-synuclein, different promoters, different animal species and different methods of protein evaluation.

This study also raises a few concerns that need to be mentioned. First, the complex changes exhibited by mice expressing A53T human $\alpha$-synuclein suggest dysfunction in other neuronal systems. The presence of $\alpha$-synuclein pathology in the motor neurons of the spinal cord may also contribute to motor deficits. Second, although dynein defects occur in the $\mathrm{SN}$, TH-expressing neurons of the SN are spared from pathology. This population of neurons may be protected from the formation of inclusions due to the lack of neuromelanin formation in mice.

\section{Conclusion}

Our results support the idea that dynein changes in the nigrostriatal system of A53T $\alpha$-synuclein transgenic mice may contribute to their severe movement disorder, which provides new information for understanding the role of dynein in $\alpha$-synuclein-linked neurodegeneration.

\section{Data availability}

figshare: Raw data from behavior tests and dynein protein levels, doi: 10.6084/m9.figshare.954933 27

\section{Author contributions}

Yan Liu performed most experiments. Yan Liu and Jian-Dong Sun analyzed the data and prepared the manuscript. Jing $\mathrm{Li}$ and Zhi-Peng Li assisted in experiments. Nai-Hong Chen and Yu-He Yuan designed the study.

\section{Competing interests}

No competing interests were disclosed.

\section{Grant information}

This work was supported by National Natural Science Foundation of China Grants (No. 30973887, No. 81073078, Key Program No. U832008), National Key Sci-Tech Major Special Item (No. 2012ZX09301002-004), and Studies on Structure and function of Bioactive Substances from Natural Medicines (IRT1007).

The funders had no role in study design, data collection and analysis, decision to publish, or preparation of the manuscript. 
1. Spillantini MG, Schmidt ML, Lee VM, et al:: Alpha-synuclein in Lewy bodies. Nature. 1997; 388(6645): 839-840.

PubMed Abstract | Publisher Full Text

2. Spillantini MG, Crowther RA, Jakes R, et al.: alpha-Synuclein in filamentous inclusions of Lewy bodies from Parkinson's disease and dementia with lewy bodies. Proc Natl Acad Sci U S A. 1998; 95(11): 6469-6473. PubMed Abstract | Publisher Full Text | Free Full Text

3. Singleton $A B$, Farrer $M$, Johnson $\mathrm{J}$, et al:: alpha-Synuclein locus triplication causes Parkinson's disease. Science. 2003; 302(5646): 841 PubMed Abstract | Publisher Full Text

4. Polymeropoulos MH, Lavedan C, Leroy E, et al.: Mutation in the alpha-synuclein gene identified in families with Parkinson's disease. Science. 1997; 276(5321): 2045-2047.

PubMed Abstract | Publisher Full Text

5. Eschbach J, Dupuis L: Cytoplasmic dynein in neurodegeneration. Pharmacol Ther. 2011; 130(3): 348-363.

PubMed Abstract | Publisher Full Text

6. Schroer TA, Steuer ER, Sheetz MP: Cytoplasmic dynein is a minus end-directed motor for membranous organelles. Cell. 1989; 56(6): 937-946. PubMed Abstract | Publisher Full Text

7. Ravikumar B, Acevedo-Arozena A, Imarisio S, et al.: Dynein mutations impair autophagic clearance of aggregate-prone proteins. Nat Genet. 2005; 37(7): 771-776.

PubMed Abstract | Publisher Full Text

8. Chung $\mathrm{CY}$, Koprich JB, Siddiqi $\mathrm{H}$, et al.: Dynamic changes in presynaptic and axonal transport proteins combined with striatal neuroinflammation precede dopaminergic neuronal loss in a rat model of AAV alpha-synucleinopathy. J Neurosci. 2009; 29(11): 3365-3373. PubMed Abstract | Publisher Full Text | Free Full Text

9. Chu Y, Morfini GA, Langhamer LB, et al:: Alterations in axonal transport motor proteins in sporadic and experimental Parkinson's disease. Brain. 2012; 135(Pt 7): 2058-2073.

PubMed Abstract | Publisher Full Text

10. Morfini G, Pigino G, Opalach K, et al:: 1-Methyl-4-phenylpyridinium affects fast axonal transport by activation of caspase and protein kinase C. Proc Natl Acad Sci U S A. 2007; 104(7): 2442-2447.

PubMed Abstract | Publisher Full Text | Free Full Text

11. Son JH, Shim JH, Kim KH, et al:: Neuronal autophagy and neurodegenerative diseases. Exp Mol Med. 2012; 44(2): 89-98. PubMed Abstract | Publisher Full Text | Free Full Text

12. Saha AR, Hill J, Utton MA, et al:: Parkinson's disease alpha-synuclein mutations exhibit defective axonal transport in cultured neurons. J Cell Sci. 2004; 117(Pt 7): 1017-1024

PubMed Abstract | Publisher Full Text

13. Giasson BI, Duda JE, Quinn SM, et al:: Neuronal alpha-synucleinopathy with severe movement disorder in mice expressing A53T human alpha-synuclein. Neuron. 2002; 34(4): 521-533

PubMed Abstract | Publisher Full Text

14. Luchtman DW, Shao D, Song C: Behavior, neurotransmitters and inflammation in three regimens of the MPTP mouse model of Parkinson's disease. Physiol. Behav. 2009; 98(1-2): 130-138.

PubMed Abstract | Publisher Full Text

15. Vila $\mathrm{M}$, Jackson-Lewis $\mathrm{V}$, Vukosavic $\mathrm{S}$, et al:: Bax ablation prevents dopaminergic neurodegeneration in the 1-methyl-4-phenyl-1,2,3,6-tetrahydropyridine mouse model of Parkinson's disease. Proc Natl Acad Sci U S A. 2001; 98(5): 2837-2842. PubMed Abstract | Publisher Full Text | Free Full Text

16. Sun JD, Liu Y, Yuan YH, et al:: Gap junction dysfunction in the prefrontal cortex induces depressive-like behaviors in rats. Neuropsychopharmacology. 2012; 37(5): 1305-1320

PubMed Abstract | Publisher Full Text | Free Full Text

17. Kong LL, Hu JF, Zhang W, et al.: Expression of chemokine-like factor 1 after focal cerebral ischemia in the rat. Neurosci Lett. 2011; 505(1): 14-18. PubMed Abstract | Publisher Full Text

18. Biju K, Zhou Q, Li G, et al:: Macrophage-mediated GDNF delivery protects against dopaminergic neurodegeneration: a therapeutic strategy for Parkinson's disease. Mol Ther. 2010; 18(8): 1536-1544. PubMed Abstract | Publisher Full Text | Free Full Text

19. Wu LM, Han H, Wang QN, et al:: Mifepristone repairs region-dependent alteration of synapsin I in hippocampus in rat model of depression. Neuropsychopharmacology. 2007; 32(12): 2500-2510. PubMed Abstract | Publisher Full Text

20. Hwang DY, Fleming SM, Ardayfio $P$, et al: 3,4-dihydroxyphenylalanine reverses the motor deficits in Pitx3-deficient aphakia mice: behavioral characterization of a novel genetic model of Parkinson's disease. J Neurosci. 2005; 25(8): 2132-2137.

PubMed Abstract | Publisher Full Text

21. Gorton LM, Vuckovic MG, Vertelkina N, et al:: Exercise effects on motor and affective behavior and catecholamine neurochemistry in the MPTP-lesioned mouse. Behav Brain Res. 2010; 213(2): 253-262.

PubMed Abstract | Publisher Full Text | Free Full Text

22. Utton MA, Noble WJ, Hill JE, et al:: Molecular motors implicated in the axona transport of tau and alpha-synuclein. J Cell Sci. 2005; 118(Pt 20): 4645-4654. PubMed Abstract | Publisher Full Text

23. Webb JL, Ravikumar B, Atkins $\mathrm{J}$, et al:: Alpha-Synuclein is degraded by both autophagy and the proteasome. J Biol Chem. 2003; 278(27): 25009-25013. PubMed Abstract | Publisher Full Text

24. De Vos KJ, Grierson AJ, Ackerley S, et al:: Role of axonal transport in neurodegenerative diseases. Annu Rev Neurosci. 2008; 31: 151-173. PubMed Abstract | Publisher Full Tex

25. Morfini GA, Burns M, Binder LI, et al:: Axonal transport defects in neurodegenerative diseases. J Neurosci. 2009; 29(41): 12776-12786. PubMed Abstract | Publisher Full Text | Free Full Text

26. Paxinos G, Franklin KBJ: The Mouse Brain in Stereotaxic Coordinates. San Diego: Academic Press; 1997. Reference Source

27. Liu Y, Yuan YH, Sun JD, et al.: Raw data from behavior tests and dynein protein levels. figshare. 2014.

Data Source 


\title{
Open Peer Review
}

\section{Current Peer Review Status: ? $\checkmark$}

\section{Version 1}

Reviewer Report 28 July 2014

https://doi.org/10.5256/f1000research.3755.r5464

(c) 2014 Acevedo-Arozena A. This is an open access peer review report distributed under the terms of the Creative Commons Attribution License, which permits unrestricted use, distribution, and reproduction in any medium, provided the original work is properly cited.

\begin{abstract}
Abraham Acevedo-Arozena
Medical Research Council (MRC) Mammalian Genetics Unit, Harwell Science and Innovation Campus, Oxford, UK

Defects in axonal transport are associated with a number of neurodegenerative disorders, including Parkinson's disease (PD). Retrograde transport in neurons is powered by the cytoplasmic dynein complex, a macromolecular structure that contains different heavy, intermediate and light dynein polypeptides.
\end{abstract}

Here, Liu et al report changes in "dynein" protein levels in a widely used mouse model of PD overexpressing mutant (A53T) a-synuclein. Interestingly, the authors found an increase in a-synuclein levels via immunoblot and immunohistochemistry in the substantia nigra (SN) of symptomatic asynuclein mutant transgenic mice. Conversely, they found a decrease in "dynein" from the striatum of the same mice. The authors used an interesting modification of the open field paradigm to test the mice for motor abnormalities. By comparing the levels of "dynein" in the striatum with the degree of motor deficits in the tested mice, the authors found a correlation between striatum dynein levels and motor performance.

\section{Comments:}

1. Although the authors refer to "dynein" levels throughout the manuscript, the antibodies they are using for immunoblot are against the cytoplasmic intermediate chain (DIC1?). This needs to be clarified in the materials and also throughout the manuscript.

2. The same applies to the immunohistochemistry. The authors report using two different anti-"dynein" antibodies, but one is against DIC (as above) and the other one against a cytoplasmic dynein light chain (DYNLT3). The authors should clarify which antibody they are using in Figure 3, as well as clarify throughout the text which cytoplasmic dynein subunits they are referring to.

3. The authors state at the end of the discussion that "although dynein defects occur in the $S N$, TH expressing neurons of the SN are spared from pathology". However, they do not show TH co-staining together with a-synuclein in Figure 3. If this statement is referring to previously 
published data, it should be referenced. If it is referring to their data, it should also appear in Figure 3.

4. In Figure 4, it appears that non-transgenic mice have also been used, together with symptomatic A53T transgenics, for the correlation between the "dynein" levels and the motor abnormalities. I would like to see the same correlation using transgenic mice only, which have obvious motor abnormalities.

Competing Interests: No competing interests were disclosed.

\section{I confirm that I have read this submission and believe that I have an appropriate level of expertise to confirm that it is of an acceptable scientific standard, however I have significant reservations, as outlined above.}

Reviewer Report 05 June 2014

https://doi.org/10.5256/f1000research.3755.r4861

(c) 2014 Morfini G. This is an open access peer review report distributed under the terms of the Creative Commons Attribution License, which permits unrestricted use, distribution, and reproduction in any medium, provided the original work is properly cited.

\section{Gerardo Morfini}

Department of Anatomy \& Cell Biology, University of Illinois at Chicago, Chicago, IL, USA

A large body of pathological evidence has established a "dying-back" pattern on degeneration for neurons affected in Parkinson's disease (PD). Indeed, axonal processes and synapses of dopaminergic neurons in the substantia nigra (SN) progressively degenerate long before these cells undergo cell death. Mechanisms underlying early degeneration of axons in PD remain unknown, but several lines of evidence have linked this critical pathogenic event to abnormalities in the function of conventional kinesin and cytoplasmic dynein (CDyn), major microtubule-based molecular motors responsible for axonal transport in adult neurons.

Consistent with these observations above, this work by Liu and collaborators reports a striking alteration in the distribution of CDyn in brains of transgenic mice expressing a PD-related mutant form of alpha synuclein (A53T-Tg mice). Immunohistochemical and immunoblotting experiments demonstrated a marked increase in levels of a specific CDyn subunit (DIC) in the SN of A53T Tg mice, compared to age-matched, non-transgenic control mice (nTg mice). Conversely, A53T-Tg mice showed decreased levels of DIC in the striatum when compared to nTg mice. Co-localization studies further suggested that this reduction in striatal DIC levels was associated to accumulation of A53T alpha-synuclein. Additionally, a highly sensitive open-field test paradigm confirmed and further extended prior reports of motor defects in A53T-Tg mice, which significantly correlated with alterations in striatal DIC levels.

Taken together, data from this paper provides novel evidence suggesting that alterations in CDyn function might contribute to disease pathogenesis associated with PD-related mutant alpha synuclein. 


\section{Comments}

1. The data presented is consistent with increased activation of CDyn-dependent retrograde axonal transport by mutant alpha synuclein. Supporting this view, prior studies showed activation of CDyn-based retrograde transport by the parkinsonian drug MPP+ (Kim-Han JS et al., J Neurosci. 2011). However, this possibility is not considered in the Discussion section.

2. CDyn is composed of multiple protein subunits including heavy (DHC) intermediate (DIC), and light (DLC) subunits, among others. In Materials and Methods, the authors report using both a monoclonal (clone 74.1; Millipore\#MAB1618), and a polyclonal (Abcam ab81507) antibody against DICs, but is unclear which one was used for immunoblots shown in Figure 2. Throughout the manuscript and in the Figure 2 legend, the text should clearly indicate that data gathered in Figure 2 corresponds to DIC subunits, rather than "dynein".

3. The authors report using an antibody from Millipore (presumably \#MAB1618 against DIC), and a polyclonal (Abcam ab121209) antibody against TcTtex (one of several DLC subunits). Again, the main text and Figure 3 legend should indicate which specific CDyn subunits are analyzed for each panel in Figure 3.

4. Some type of quantitation could be provided to illustrate the negative correlation between TcTtex levels and A53T alpha-synuclein accumulation.

\section{Minor comments}

1. The authors mention that the major finding in their study is that changes in CDyn expression occurred in the nigrostriatal system of A53T human a-synuclein Tg mice. However, the experiments performed do not directly address protein expression. Rather, those evaluate overall DIC steady state levels.

2. To ensure reproducibility of results by other investigators, please provide the lot number for Abcam polyclonal antibodies \#ab81507 and \#ab121209.

Competing Interests: No competing interests were disclosed.

\section{I confirm that I have read this submission and believe that I have an appropriate level of expertise to confirm that it is of an acceptable scientific standard.}

Reviewer Report 06 May 2014

\section{https://doi.org/10.5256/f1000research.3755.r4454}

(C) 2014 Koprich J. This is an open access peer review report distributed under the terms of the Creative Commons Attribution License, which permits unrestricted use, distribution, and reproduction in any medium, provided the original work is properly cited. 


\section{James B Koprich}

Toronto Western Research Institute, Toronto Western Hospital, University Health Network, Toronto, ON, Canada

\section{Summary}

In this paper by Liu et al. a relationship between alpha-synuclein accumulation, motor deficits and expression of dynein in the nigrostriatal pathway is described. The study used transgenic mice overexpressing A53T aSyn similar to the M83 line and age matched Wt littermate controls. A behavioural deficit was confirmed in the Tg mice using a modified open-field test. The Tg mice showed reduced exploration and increased latency to get down from the starting platform. Mice were then sacrificed and tissue was prepared for western blot of dynein and immunohistochemistry of dynein and aSyn. The results showed decreased levels of dynein in the striatum and increased levels in the $\mathrm{SN}$, both from western blots and histology. Furthermore, the authors showed that dynein levels were reduced in neurons with higher level of aSyn.

\section{Comments}

1. The number of animals used in each analysis needs to be provided along with the degrees of freedom for each statistical test performed.

2. The staining in Fig 3, panel F has much more background compared to its counterpart in panel E. Please confirm that cases from different groups were all stained together to rule out any histology related confounds.

3. The results from Fig 3 panels I, J and $\mathrm{K}$ are taken from a single region of a single case. Random sampling within the region of interest should be performed on each case (compared to Wt controls) to arrive at any conclusion. Optical density or fluorescent intensity measures should be obtained in the process to provide a quantitative assessment.

4. The co-staining in Fig 3, panel $\mathrm{K}$ should include $\mathrm{TH}$ to know that the neurons being analyzed are SN dopamine neurons as alluded to in the conclusion.

Competing Interests: No competing interests were disclosed.

I confirm that I have read this submission and believe that I have an appropriate level of expertise to confirm that it is of an acceptable scientific standard, however I have significant reservations, as outlined above. 
The benefits of publishing with F1000Research:

- Your article is published within days, with no editorial bias

- You can publish traditional articles, null/negative results, case reports, data notes and more

- The peer review process is transparent and collaborative

- Your article is indexed in PubMed after passing peer review

- Dedicated customer support at every stage

For pre-submission enquiries, contact research@f1000.com 